\title{
Patient Satisfaction: A Comparison between Governmental and Private Out Patient Clinics in Taif, Saudi Arabia
}

\author{
Waleed S Mohamed ${ }^{1 \star}$, Khalid Swat ${ }^{1}$, Moustafa A Wahab ${ }^{2}$, Adnan A Alsulaimani ${ }^{3}$, and April J Portugal ${ }^{4}$ \\ ${ }^{\prime}$ Department of Internal Medicine, College of Medicine, Taif University, KSA \\ ${ }^{2}$ Dental Specialist and Quality Coordinator at Taif University Outpatient Clinic, KSA \\ ${ }^{3}$ Department of Pediatrics, College of Medicine, Taif University, KSA \\ ${ }^{4}$ Nursing Director, AL-Ameen Hospital, KSA
}

\section{Article Info}

\author{
*Corresponding author: \\ Waleed S Mohamed \\ Professor \\ Department of Internal Medicine \\ Taif College of Medicine \\ Tanta University \\ Egypt \\ Tel: +20/01011496110 \\ E-mail: wsmohamed1@yahoo.com
}

Received: July 19, 2016

Accepted: December 3, 2016

Published: January 7, 2017

Citation: Mohamed WS, Swat K, Wahab MA, Alsulaimani AA, Portugal AJ. Patient Satisfaction: A Comparison between Governmental and Private Out Patient Clinics in Taif, Saudi Arabia. Madridge J Case Rep Stud. 2017; 1(1): 1-6.

doi: $10.18689 /$ mjcrs-1000101

\section{Copyright: @ 2017 The Author(s). This work is licensed under a Creative Commons Attribution 4.0 International License, which permits unrestricted use, distribution, and reproduction in any medium, provided the original work is properly cited.}

Published by Madridge Publishers

\begin{abstract}
Objective: This study aimed to identify and compare the factors that contribute to patient satisfaction towards the medical care services between governmental and private healthcare clinics.
\end{abstract}

Methods: A self- administrated (Arabic/English) questionnaire was used to conduct the all participants. Participants were selected using convenience sampling for both the governmental and private clinics.

Results: Participated were 141 patients from the government clinics and 215 patients from private clinics. $75 \%$ of the patients were Saudi, $49.1 \%$ were male patients. Opinion about level of care provided was significantly higher in AL-Ameen Hospital outpatient clinic (AHOC) (77\%) than Taif University outpatient clinic (TUOC) (59\%), the physician explain way of taking medication was $(42 \%)$ in TUOC compared to $(55 \%)$ in AHOC. Waiting time $>30$ Min was (7.09\%) in TUOC while it was (30.70\%) in AHOC. The time spent during examination $>30$ Min was (3.55\%) in TUOC while it was $(7.91 \%)$ in AHOC. Satisfaction about working hours was significantly less in TUOC (29\%) compared to $(44 \%)$ in $\mathrm{AHOC}$.

Conclusion: Although patients at the AHOC were more satisfied than those at TUOC with the health care they received, eight of the predictors of patient satisfaction in this study were common to both settings.

Keywords: Patient satisfaction; Medical care Quality; Governmental and Private Outpatient Clinic.

\section{Introduction}

According to Gambrill the primary medical care is defined as the point at which a member of the community can make a decision to consult a professional such as a physician or semiprofessional medical care, worker regarding his/her medical problem [1], which he or she believes that person may help to solve it [2]. In another way primary medical care is the daily health care given by a health care provider. This provider, in the primary medical care acts as the first contact and principal point of continuing care for patients within a healthcare system and coordinates other specialist care that the patient may need. 
Child health care, community participation, health education, chronic disease management, immunization, management of communicable diseases, baby-maternal healthcare and environmental health are the main aspects of primary care which are covered in the Saudi Ministry of health guidelines [3]. The Saudi governmental health care system provides all the services for the entire citizen and the eligible foreigner patients for free, that includes, but not limited to physician consultation, operation, out/inpatient services, diagnostic procedures and all prescribed medications. The Ministry of Health (MOH) operates 1787 primary care centers throughout the country, each one serving an average of 8727 people [3].

In 1993, national guidelines for quality assurance in primary care were established in Saudi Arabia and promotion of quality has always been an integral part of primary health care programs [4]. Also primary health care is provided by private sectors [24]. Many patients believe that private outpatient clinics are superior to governmental one. For that it's preferable even if they are going to pay for it. Sometimes the medical service provided by the private outpatient clinic is covered with third party. The private outpatient clinic may have some advantages over the governmental one as the patient can choose his doctor, shorter waiting times, improved facilities, no queues, private room, high personal care and continuity of care as patients are likely to be seen by the same consultant throughout their treatment. However, the private outpatient clinic has a high cost and seldom covers all medical services [5].

Patient satisfaction is not a new concept. Patients are one of the main stakeholders among the ever expanding modern world of medicine. The contexts and backdrops have undergone tremendous changes over time, although the roles of patients and doctors have remained fixed.

It is known that the doctor-patient relationship has been and remains a keystone of care: the medium in which data are gathered, diagnoses, and plans are made, compliance is accomplished, and healing, patient activation, and support are provided [6]. Satisfaction with the doctor-patient relationship is a critical factor in people's decisions to join and stay with a specific organization [7].

Assessment of patients' satisfaction level is now one of the five World Health Organization (WHO) indicators to improve the quality of healthcare services [8]. The most important thing in bridging the gap between the actual care given and the care that should have been given are patients' perceptions [9]. Patients' satisfaction is determined by both their expectations regarding the healthcare they are about to receive and their perceptions of past healthcare [10]. All these dimensions are included in the patients' satisfaction: technical quality of care, art of care, accessibility and convenience, physical environment, finances, continuity of care, availability, efficacy and outcome of care. The working definition is the degree to which the patients' desired expectations, goals and preferences are met by the healthcare provider and service [11]. It has been shown that patients' satisfaction with health services is affected by various factors such as nurses, assisting personnel, physician and the physical environment of the hospital [10]. It is easy also to predict future behaviors of patients during the treatment course and after discharge. In contrast, outpatient clinics are always considered the first contact place between patients and healthcare systems [11]. Therefore, assessment of the satisfaction level of the patients would provide a great chance to evaluate the invisible aspects of services, such as waiting time, in order to prevent wasting of resources and finally to reduce the costs of healthcare services [12]. Many studies have shown that a greater satisfaction level of patients with physicians' behavior and their consultations during the period of treatment encourages them to follow physicians' recommendations and orders better [13].

Hence the aim of this work is to determine patient satisfaction in TUOC and compares our results (Governmental) with $\mathrm{AHOC}$ which is one of the most famous private outpatient clinics in Taif city, Saudi Arabia.

\section{Methodology}

This study was done using convenience sampling design. A self-administered (Arabic/English) questionnaire was used to conduct the interviews. Participants were selected using convenience sampling for both the governmental and private clinics. This study employed a self-administered questionnaire that required less than 10 minutes to be completed. The questionnaire used has face validity was established experts. It was pilot tested on a subset of participants with principal components analysis and revision and has been thought to be an efficient and effective tool for collecting information. The patients/respondents were consecutively selected and a questionnaire was developed to evaluate their satisfaction regarding the availability, accessibility and convenience for both services in governmental and private outpatient clinics, including their perception about the behavior of staff, including a list of the amenities that they feel are important to them as clients. A Random sampling technique over a fivemonth period was employed starting from February 1 st till the end of June 2015. All patients accepted to participate in this study. The questionnaire was based designed to measure the criteria affecting patient-physician interaction (6 items) and patients' satisfaction with administrative efficiency and clinic setup environment (8 items).

The questionnaire was drafted in the Arabic and English with a 5 -point Likert response scale ranging from 1 (strongly disagree) to 5 (strongly agree. Mixtures of negative and positive statements were set to ensure that there is no standard format for answering. Therefore, participants needed to read each item carefully before responding. The irrelevant questions were dropped. Irrelevant questions were identified as the questions which were not answered by the participants. A questionnaire was administered voluntary and anonymous in private setting with guidance. Percentages of agreement on the 2 main disciplines of satisfaction were calculated and presented; the mean percentages of satisfaction were calculated to estimate the overall ranking analysis of individual satisfaction disciplines. 


\section{Statistical analysis}

The data were coded and keyed into the Statistical Package for the Social Sciences software version 20 (SPSS Inc., Chicago, IL) used in Windows 7. Descriptive analysis followed by inferential statistics was done. Percentages and means were calculated for qualitative and quantitative data. T-test and Chi-square test (X2) were performed to statistically analyze qualitative data. A P-value of 0.05 was considered.

\section{Ethical consideration}

The Research Ethics Committee of the College of Medicine, Taif University, approved this study. The waiver of the informed consent process was approved on the basis of the questionnaire's being anonymous and self-administered and containing no identifiers so that patients did not feel threatened in any way for their choice of clinic and participating in the study.

\section{Results}

A Total of 356 patients were participated, comprising 141 patients from the government clinics and 215 patients from private clinics. About $75 \%$ of the patients were Saudi $70.2 \%$ in TUOC and $78.6 \%$ in AHOC with no statistical significant difference ( $p=0.0748)$; Male patients were (49.1\%) with $41.8 \%$ in TUOC and $54.0 \%$ in AHOC with a statistical significant difference $(p=0.0059)$. As regards education level, there was a statistical significant difference between both groups $(p=0.0040)$ where, patient with university degree were the majority of the patients in TUOC (56.03\%) and (51.16\%) in AHOC, participants with only High school (HS) education level was significantly higher in AHOC (40.93\%) in comparison to TUOC (29.79\%) while patients with post graduate degree was significantly higher in TUOC (14.18\%) compared to (7.91\%) for AHOC. As regards age, there was no statistical significant difference between both age groups (Table 1). Participants' satisfaction as regard patient-physician interaction revealed no statistical significant difference between both groups as regard physician respect during examination $(p=0.4524)$, physician listen carefully $(p=0.9386)$, the physician explains condition in a clear way $(p=0.9657)$, physician answer all patients' questions $(p=0.5609)$ where, the physician explain way of taking medication in the government outpatient clinic (GOPD) was (42\%) compared to (55\%) in the AHOC with statistically significant difference between both groups $(p=0.0159)$. Treat patients' chief complaint in the government outpatient clinic (GOPD) was (26.24\%) compared to (35.81\%) in the AHOC with statistically significant difference between both groups $(\mathrm{p}=0.0469)$ (Table 2).

Participants' satisfaction as regard administrative efficiency and clinic setup environment questionnaire details revealed no statistical significant difference between both groups as regard Time spent during examination $(p=0.4682)$, working hours $(p=0.2918)$, cleanliness level $(p=0.2518)$ and recommendation $(p=0.7311)$ where, waiting time less than 15 minutes was (68.09\%) in the TUOC compared to (31.6\%) in the AHOC with statistically significant difference between both groups $(p=0.0000)$. As regards difficult location, there was statistically significant difference between both groups $(p=0.0106)$ where it was much less for TUOC compared to AHOC. Medication availability was (21.99\%) in the TUOC compared to (32.56\%) in the AHOC with statistically significant difference between both groups $(p=0.0097)$. Finally, opinion about the level of care provided was higher in AHOC (77\%) than TUOC (59\%) with statistically significant difference between both groups $(p=0.0014)$ (Table 3$)$.

\section{Discussion}

Health care is a serious concern and a point to ponder about for practitioners, researchers and government officials. A variety of steps have been taken by the government of the kingdom of Saudi Arabia to improve the quality of patient care. Good Quality of care is the right of ill people to get better health services. Health care in kingdom of Saudi Arabia is divided into two categories; governmental and private. Private sector hospitals are in the business of health care. People belong to high income level always prefer private outpatient clinic as they can afford medical expenses, While people who belong to lower income group prefer the governmental outpatient clinic as the treatment is given free of fees. In the governmental sector, provincial governments are given authorities to make rules and regulations. While in private sectors, there is no control of government. It is very necessary to improve the service quality of both governmental and private sectors [12]. This study attempted to assess the level of satisfaction of the patients with the various aspects of health care in government and private health facilities in Taif, KSA and compare between them. According to our knowledge this may be the first study that was being done in the kingdom of Saudi Arabia about this point and therefore we had limited data for the comparison between past and present. In our study we evaluated the level of satisfaction among patients who are attending in AHOC compared to those attending in TUOC and the majorities of those participants were Saudi. Interestingly, health care providers in both settings were from the same clinical, cultural and educational background. It was noticeable that the level of patient satisfaction was higher in those attending AHOC. Patients seen in TUOC were more likely to have higher educational level, but were less satisfied compared to those with lower educational level seen at the AHOC. Although patient education significantly correlated with the level of satisfaction in one study [13]. Ganasegeran in 2015 found that patients with high school education perceived a significantly higher service satisfaction in comparison to tertiary graduates [14], inconsistent with a AHOC. Although a recent study showed that long waiting time is negatively associated with patient satisfaction [16-25]. In 2001 it was found that all the service, quality dimensions had significant relationship with patients' satisfaction. In the overall results of the present study indicate that patients in governmental sector hospital are more satisfied than the private one [17]. These are contrary to the results of Taner and Antony 2006 [18], where patients in private hospitals are more satisfied.previous finding from Uganda. The lower patient satisfaction score relative to high school education may be due to a potentially greater service expectation by the more highly educated patients [15]. Services 


\section{Madridge Journal of Case Reports and Studies}

provided in the TUOC were totally free of charges compared to the AHOC where patients should pay for all services provided or covered with third party. Waiting time for more than 30 min is higher in $\mathrm{AHOC}$ compared to TUOC while patients in $\mathrm{AHOC}$ were more satisfied. It's possibly because of the long patient-physician interaction time that was reported at the

Table 1. Participants' related general data

\begin{tabular}{|c|c|c|c|c|c|c|c|c|c|c|c|}
\hline \multirow{3}{*}{ Nationality } & \multicolumn{5}{|c|}{ TUOC } & \multicolumn{5}{|c|}{$\mathrm{AHOC}$} & \multirow{2}{*}{$P$} \\
\hline & \multicolumn{2}{|c|}{ Saudi } & \multicolumn{2}{|c|}{ Non - Saudi } & Total & \multicolumn{2}{|c|}{ Saudi } & \multicolumn{2}{|c|}{ Non - Saudi } & Total & \\
\hline & \multicolumn{2}{|c|}{99 (70.2\%) } & \multicolumn{2}{|c|}{$42(29.8 \%)$} & 141 & \multicolumn{2}{|c|}{169 (78.6\%) } & \multicolumn{2}{|c|}{$46(21.4 \%)$} & 215 & 0.0748 \\
\hline \multirow{2}{*}{ Gender } & \multicolumn{2}{|c|}{ Male } & \multicolumn{2}{|c|}{ Female } & Total & \multicolumn{2}{|c|}{ Male } & \multicolumn{2}{|c|}{ Female } & Total & \multirow{2}{*}{$0.0059^{*}$} \\
\hline & \multicolumn{2}{|c|}{59 (41.8\%) } & \multicolumn{2}{|c|}{82 (58.2\%) } & 141 & \multicolumn{2}{|c|}{116 (54.0\%) } & \multicolumn{2}{|c|}{99 (46.0\%) } & 215 & \\
\hline \multirow{2}{*}{ Education level } & HS & U & \multicolumn{2}{|c|}{ PG } & Total & HS & U & \multicolumn{2}{|c|}{ PG } & Total & \multirow{2}{*}{$0.0040^{\star}$} \\
\hline & $29.79 \%$ & $56.03 \%$ & \multicolumn{2}{|c|}{$14.18 \%$} & $100 \%$ & $40.93 \%$ & $51.16 \%$ & \multicolumn{2}{|c|}{$7.91 \%$} & $100 \%$ & \\
\hline \multirow{2}{*}{ Age } & $<18$ & $19-40$ & $>50$ & $41-50$ & Total & Total & $>50$ & $41-50$ & $19-40$ & $<18$ & \multirow{2}{*}{$0.0729^{\star}$} \\
\hline & $67.38 \%$ & $9.93 \%$ & $9.22 \%$ & $13.48 \%$ & $100 \%$ & $100 \%$ & $7.91 \%$ & $17.21 \%$ & $66.04 \%$ & $8.84 \%$ & \\
\hline
\end{tabular}

* Significant $p<0.05$

Table 2. Participants' satisfaction as regard patient-physician interaction questionnaire details.

\begin{tabular}{|c|c|c|c|c|c|c|c|}
\hline Question & \multicolumn{6}{|c|}{ Answer [No (\%)] } & \multirow{2}{*}{$p$} \\
\hline \multirow{3}{*}{ Physician respect during examination } & Group & No & Rarely & Sometimes & Often & Always & \\
\hline & TUOC & $6.38 \%$ & $5.67 \%$ & $11.35 \%$ & $20.57 \%$ & $56.03 \%$ & \multirow{2}{*}{0.4524} \\
\hline & AHOC & $6.08 \%$ & $2.34 \%$ & $9.81 \%$ & $23.36 \%$ & $58.41 \%$ & \\
\hline \multirow{3}{*}{ Physician listen to you carefully } & Group & No & Rarely & Sometimes & Often & Always & \multirow{3}{*}{0.9386} \\
\hline & TUOC & $0.71 \%$ & $4.96 \%$ & $12.06 \%$ & $43.75 \%$ & $43.26 \%$ & \\
\hline & $A H O C$ & $3.26 \%$ & $4.65 \%$ & $13.02 \%$ & $27.91 \%$ & $48.37 \%$ & \\
\hline \multirow{3}{*}{ Physician explain your condition in clear way } & Group & No & Rarely & Sometimes & Often & Always & \multirow{3}{*}{0.9657} \\
\hline & TUOC & $4.97 \%$ & $4.96 \%$ & $12.06 \%$ & $34.75 \%$ & $43.26 \%$ & \\
\hline & $A H O C$ & $6.05 \%$ & $4.65 \%$ & $13.02 \%$ & $27.91 \%$ & $48.37 \%$ & \\
\hline \multirow{3}{*}{ Did the physician answer all your questions } & Group & No & Rarely & Sometimes & Often & Always & \multirow{3}{*}{0.5609} \\
\hline & TUOC & $4.26 \%$ & $3.55 \%$ & $19.15 \%$ & $24.11 \%$ & $48.94 \%$ & \\
\hline & AHOC & $6.52 \%$ & $3.26 \%$ & $11.16 \%$ & $22.79 \%$ & $56.28 \%$ & \\
\hline \multirow{3}{*}{ Physician explain way of taking medication } & Group & No & Rarely & Sometimes & Often & Always & \multirow{3}{*}{$0.0159^{*}$} \\
\hline & TUOC & $18.44 \%$ & $3.55 \%$ & $14.89 \%$ & $21.28 \%$ & $41.84 \%$ & \\
\hline & $A H O C$ & $11.63 \%$ & $4.19 \%$ & $10.23 \%$ & $18.60 \%$ & $55.35 \%$ & \\
\hline \multirow{3}{*}{ Treat your chief complaint } & Group & No & Rarely & Sometimes & Often & Always & \multirow{3}{*}{$0.0469 *$} \\
\hline & TUOC & $18.44 \%$ & $4.96 \%$ & $21.99 \%$ & $28.37 \%$ & $26.24 \%$ & \\
\hline & AHOC & $15.82 \%$ & $1.86 \%$ & $14.42 \%$ & $32.09 \%$ & $35.81 \%$ & \\
\hline
\end{tabular}

* Significant $p<0.05$

Table 3. Participants' satisfaction as regard administrative efficiency and clinic setup environment questionnaire details.

\begin{tabular}{|c|c|c|c|c|c|c|c|}
\hline Question & \multicolumn{6}{|c|}{ Answer [No (\%)] } & \multirow{2}{*}{$P$} \\
\hline \multirow{3}{*}{ Waiting time } & Group & \multicolumn{2}{|c|}{$<15$ Min } & 15-30 Min & \multicolumn{2}{|c|}{$>30$ Min } & \\
\hline & TUOC & \multicolumn{2}{|c|}{$68.09 \%$} & $24.82 \%$ & \multicolumn{2}{|c|}{$7.09 \%$} & \multirow{2}{*}{$0.0000^{*}$} \\
\hline & $\mathrm{AHOC}$ & \multicolumn{2}{|c|}{$31.63 \%$} & $37.67 \%$ & \multicolumn{2}{|c|}{$30.70 \%$} & \\
\hline \multirow{3}{*}{ Time spent during examination } & Group & \multicolumn{2}{|c|}{$<15$ Min } & 15-30 Min & \multicolumn{2}{|c|}{$>30 \mathrm{Min}$} & \multirow{3}{*}{0.4682} \\
\hline & TUOC & \multicolumn{2}{|c|}{$75.89 \%$} & $20.57 \%$ & \multicolumn{2}{|c|}{$3.55 \%$} & \\
\hline & $\mathrm{AHOC}$ & \multicolumn{2}{|c|}{$70.24 \%$} & $21.86 \%$ & \multicolumn{2}{|c|}{$7.91 \%$} & \\
\hline \multirow{3}{*}{ Difficult location } & Group & No & Rarely & Sometimes & Often & Always & \multirow{3}{*}{$0.0106^{*}$} \\
\hline & TUOC & $60.99 \%$ & $9.22 \%$ & $21.99 \%$ & $2.84 \%$ & $4.96 \%$ & \\
\hline & $\mathrm{AHOC}$ & $45.33 \%$ & $14.95 \%$ & $24.77 \%$ & $7.01 \%$ & $7.94 \%$ & \\
\hline \multirow{3}{*}{ Medication availability } & Group & No & Rarely & Sometimes & Often & Always & \multirow{3}{*}{$0.0097^{*}$} \\
\hline & TUOC & $14.19 \%$ & $8.51 \%$ & $24.82 \%$ & $30.50 \%$ & $21.99 \%$ & \\
\hline & $\mathrm{AHOC}$ & $10.24 \%$ & $2.79 \%$ & $19.53 \%$ & $34.88 \%$ & $32.56 \%$ & \\
\hline \multirow{3}{*}{ Working hours } & Group & No & Rarely & Sometimes & Often & Always & \multirow{3}{*}{0.2918} \\
\hline & TUOC & $19.15 \%$ & $7.09 \%$ & $17.73 \%$ & $26.95 \%$ & $29.08 \%$ & \\
\hline & $\mathrm{AHOC}$ & $16.74 \%$ & $4.19 \%$ & $20.93 \%$ & $24.65 \%$ & $33.49 \%$ & \\
\hline \multirow{3}{*}{ Opinion about level of care provided } & Group & Bad & Poor & Fair & Good & Excellent & \multirow{3}{*}{$0.0014^{*}$} \\
\hline & TUOC & $14.9 \%$ & $4.26 \%$ & $21.99 \%$ & $34.04 \%$ & $24.82 \%$ & \\
\hline & $\mathrm{AHOC}$ & $10.7 \%$ & $0.93 \%$ & $11.63 \%$ & $33.02 \%$ & $43.72 \%$ & \\
\hline \multirow{3}{*}{ Cleanliness level } & Group & Bad & Poor & Fair & Good & Excellent & \multirow{3}{*}{0.2518} \\
\hline & TUOC & $14.19 \%$ & $2.84 \%$ & $9.93 \%$ & $26.95 \%$ & $46.10 \%$ & \\
\hline & $\mathrm{AHOC}$ & $8.84 \%$ & $1.86 \%$ & $11.16 \%$ & $33.49 \%$ & $44.65 \%$ & \\
\hline \multirow{3}{*}{ Recommendation } & Group & No & Rarely & Sometimes & Often & Always & \multirow{3}{*}{0.7311} \\
\hline & TUOC & $17.02 \%$ & $4.26 \%$ & $19.86 \%$ & $23.40 \%$ & $35.46 \%$ & \\
\hline & $\mathrm{AHOC}$ & $14.49 \%$ & $5.14 \%$ & $23.36 \%$ & $21.03 \%$ & $35.98 \%$ & \\
\hline
\end{tabular}

* Significant $p<0.05$ 
Nasim and Janjua 2014 [19], stated that in the private sector, patients demand more responsive attitude from staff and doctors, as patients have to pay from their pocket for all the services they are getting. The private sector is efficient enough to show responsiveness towards patients and hence a source of their satisfaction. Patients in the private sector are not satisfied with the level of communication of doctors and staff. They demand a high level of communication that may lead to their satisfaction. They demand that each and everything about their treatment and tests should be explained to them in detail and sometimes doctor feel reluctant to provide this information, considering the sensitive health condition of patients. Patients were more satisfied with the working hours offered at the AHOC and that is expected as the AHOC work for two shifts with five of the working hours after $4 \mathrm{pm}$ while in the TUOC physicians work for one shift until $2 \mathrm{pm}$. In addition, the AHOC works for an additional 2 hours per day. A recent study showed that the after-hours care correlated positively with the patient satisfaction [20]. In general, in our study, the physician patient interaction parameters weren't different between the $\mathrm{AHOC}$ and the TUOC. Although more patients at the AHOC received education about the prescribed medications and felt more satisfied with treating their chief complaint. This particular area can be improved by the targeted physician interactive educational sessions [21].

It is clear in our study that despite the convenient location for the TUOC, the patients attending in the AHOC were more satisfied and that can be explained by some of the best parameters related to physician patient interaction which is seen in the AHOC. Overall satisfaction was explained in the question regarding to the opinion about the level of care provided which was significantly higher in $\mathrm{AHOC}$ with $77 \%$, while in TUOC was with $59 \%$ and it must be increased to reach the benchmark which is 70\% [22]. Tateke et al 2012 concluded that, although patients in the private sector were more satisfied than those at the governmental one with the healthcare they received, five of the predictors of patient satisfaction in this study were common to both settings [23]. According to the results of the present study, we reach to some conclusions. Governmental and private sectors are a source of satisfaction for patients in some aspects, but in other ones they are not that much satisfied for patients.

The strength of this study is its novelty and being the first one in such area in Kingdom of Saudi Arabia as we compared the self-paid healthcare with the government paid health care that was delivered by the physicians with similar training, cultural background and multiple areas in the care and the environment that was assessed while. The study weakness includes the relatively small sample size and the educational background of the patients.

\section{Conclusion}

Although patients at the private outpatient clinic (AHOC) were more satisfied than those at the government outpatient clinic (TUOCD) with the healthcare they received, eight of the predictors of patient satisfaction in this study were common to both settings. This study provides important information that could be used by to monitor and improve the quality of medical care in the respective sector. Findings can be used for imparting training to medical staff to increase patient satisfaction.

\section{Recommendation}

More physician focused training to improve the care provided are needed to increase service quality and improve patient satisfaction. Future larger and representative sample is recommended are needed to confirm our findings. The crosssectional nature of the study limits our ability to find causal inferences. Data obtained in this study was from a single clinic; this may affect the generalizability of the results to all medical outpatients.

\section{References}

1. Gambrill E. Organization of primary care In: primary care. John Fry, (Eds) William Heinemann Medical Books Ltd, London, 1980.

2. Scientific Committee for Quality Assurance. Guidelines for Quality Assurance in Primary Healthcare. Saudi Arabia: Ministry of Health, 1993.

3. Ministry of Health. Health Statistical Year Book. Saudi Arabia: MOH, 2002.

4. Khoja T. Quality assurance in primary healthcare: Saudi Arabia's experience. In Al-Assaf A., Ed., Health Care Quality: An International Perspective. New Delhi: WHO Regional Publications, SEARO, No. 35.

5. Norton-Westwood D, Robertson-Malt S, Anderson R. A randomized controlled trial to assess the impact of an Admission Service on patient and staff satisfaction. Int J Nurs Pract. 2010; 16(5): 461-471. doi: 10.1111/j.1440-172X.2010.01870.x

6. Lipkin MJ, Putnam SM, Lazare A, et al. The Medical Interview: Clinical Care, Education, and Research. New York, NY: Springer-Verlag. 1995; doi: 10.1007/978-1-4612-2488-4

7. Sofaer S, Hurwicz ML. When medical group and HMO part company: disenrollment decisions in Medicare HMOs. Med Care 1993; 31(9): 808-21.

8. Silbertstein N. Are patients' satisfaction surveys a good idea? Podiatry Management .Academic Journal. 2010; 29(03):113.

9. Hatamizadeh N, Jafary P, Vameghi R, Kazemnezhad A. Factors affecting client satisfaction and dissatisfaction in outpatient rehabilitation centers in Kurdistan province in Iran. Iran Red Crescent Med J. 2012; 14:119-20.

10. Ko HH, Zhang $\mathrm{H}$, Telford JJ, Enns R. Factors influencing patients 'satisfaction when undergoing endoscopic procedures. Gastrointest Endosc 2009; 69:883-91.

11. Wiggers JH, Donovan KO, Redman S, Sanson-Fisher RW. Cancer patients satisfaction with care. Cancer.1990; 66: 610-16.doi: 10.1002/1097-0142

12. Nasim K, Janjua S. Service quality perceptions and patients' satisfaction: A comparative case study of a public and private sector hospital in Pakistan. International Journal for Quality Research. 2014; 8(3): 447-60.

13. Zandbelt LC, Smets EM, Oort FJ, Godfried MH, de Haes HC. Satisfaction with the outpatient encounter: a comparison of patients' and physicians' views. J Gen Intern Med 2004 Nov.

14. Ganasegeran K, Perianayagam W, AbdulManaf R, Jadoo S, Al-Dubai S. Patient Satisfaction in Malaysia's Busiest Outpatient Medical Care. The Scientific World Journal. 2015; 1-6.

15. J. Nabbuye-Sekandi, F. E. Makumbi, A. Kasangaki et al., "Patient satisfaction with services in outpatient clinics at Mulago hospital, Uganda," International Journal for Quality in Health Care 2011; vol. 23, no. 5, pp. 516-523.

16. Bleustein C, Rothschild DB, Valen A, Valatis E, Schweitzer L, Jones R. Wait times, patient satisfaction scores, and the perception of care. Am J Manag Care. 2014 May. 
17. Andaleeb, S.S. Service quality perceptions and patient satisfaction: a study of hospitals in a developing country. Social Science \& Medicine. 2001; 52: 1359-70.

18. Taner, T., \& Antony, J. Leadership in health services: Comparing public and private hospital care service quality in Turkey. Leadership in Health Services. 2006; 19(2): 1-10.

19. Jackson JL, Chamberlin J, Kroenke K. Predictors of patients' satisfaction. Soc Sci Med. 2001; 52: 609-20.

20. Howard, Michelle et al. "Patient Satisfaction With Care for Urgent Health Problems: A Survey of Family Practice Patients." Annals of Family Medicine. 5.5 (2007): 419-24. PMC. Web. 17 Oct. 2015. doi: 10.1370/ afm.704

21. Tarn, Derjung M. et al. "Intervention to Enhance Communication About Newly Prescribed Medications." Annals of Family Medicine. 2015; 28-36. doi: 10.1370/afm.1417
22. Hossain S, Ferdousi J, Biswas M, Mahfuz N, Biswas G. Quality of Care: View of Patient Satisfaction with Physiotherapy in Government and Private Settings in Dhaka, Bangladesh. Faridpur Med. Coll. J 2012; 7(2): 71-4. DOI: http://dx.doi.org/10.3329/fmcj.v7i2.13502

23. Tateke $T$, Woldie M, Ololo S. Determinants of patient satisfaction with outpatient health services at public and private hospitals in Addis Ababa, Ethiopia. Afr J Prm Health Care Fam Med. 2012; 4(1): 1-11. doi: 10.4102/ phcfm.v4i1.384

24. Khattak A, Alvi MI, Yousaf MA, Shah SZ, Turial D, Akhter S. Patient Satisfaction-A Comparison between Public \& Private Hospitals of Peshawar. International Journal of Collaborative Research on Internal Medicine \& Public Health. 2012; 4(5): 713-22.

25. Wetmore S, Boisvert L, Graham E, et al. Patient satisfaction with access and continuity of care in a multidisciplinary academic family medicine clinic. Canadian Family Physician 2014; 60(4): e230-e36. 